\title{
Hormonal Contraceptive Use After Venous Thrombosis: Practice From 1999 to 2004
}

\author{
Bernardine H. Stegeman ${ }^{\mathrm{a}, \mathrm{b}, \mathrm{c}}$, Hetty Jolink ${ }^{\mathrm{d}}$, Frans M. Helmerhorst ${ }^{\mathrm{e}, \mathrm{f}}$, Frits R. Rosendaal ${ }^{\mathrm{a}, \mathrm{b}, \mathrm{e}}$, \\ Astrid van Hylckama Vlieg ${ }^{\mathrm{b}, \mathrm{e}, \mathrm{g}}$
}

\begin{abstract}
Background: Current guidelines state that women using combined hormonal contraceptives should stop using these preparations after a venous thrombosis. The aim of this study was to assess to what extent these guidelines are followed in daily practice.
\end{abstract}

Methods: Women younger than 50 years with a hormonal contraceptive-associated venous thrombosis were selected from the Multiple Environmental and Genetic Assessment of risk factors for venous thrombosis (MEGA) study. Data on hormonal contraceptive use after the event and advice from a physician were collected at venepuncture and through a follow-up study, respectively. Risk differences (RDs) with $95 \%$ confidence interval (95\% CI) were calculated.

Results: Seven hundred three women were included with a mean follow-up at venepuncture of 10.8 months (range: 2.1 to 35.4 months). Five hundred twenty-one (74\%) women stopped hormonal contraceptive use, $63(9 \%)$ changed to a different preparation and $119(17 \%)$ continued to use their preparation. One hundred fortythree $(21 \%)$ of 682 women using a combined oral contraceptive at

Manuscript accepted for publication May 29, 2014

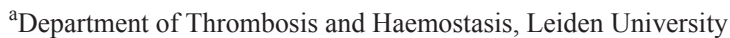
Medical Center, Leiden, The Netherlands

${ }^{\mathrm{b}}$ Einthoven Laboratory for Experimental Vascular Medicine, Leiden University Medical Center, Leiden, The Netherlands

${ }^{\mathrm{c}}$ Department of Epidemiology and Public Health, University College London, London, UK

${ }^{\mathrm{d}}$ Department of Infectious Diseases, Leiden University Medical Center, Leiden, The Netherlands

${ }^{\mathrm{e}}$ Department of Clinical Epidemiology, Leiden University Medical Center, Leiden, The Netherlands

${ }_{\mathrm{f}}$ Department of Gynaecology and Reproductive Medicine, Leiden University Medical Center, Leiden, The Netherlands

${ }^{\mathrm{g}}$ Corresponding Author: Astrid van Hylckama Vlieg, Department of Clinical Epidemiology, C7-P, Leiden University Medical Center, PO Box 9600, 2300 RC Leiden, The Netherlands.

Email: a.van_hylckama_vlieg@1umc.nl

doi: http://dx.doi.org/10.14740/jem221w the thrombotic event were still using a combined preparation after the event. Women who continued their contraceptive use had less often a positive family history of venous thrombosis and more often surgery (RD 19\% (95\% CI: 9 to $30 \%)$ ) or a plaster cast (RD $17 \%(95 \%$ CI: 3 to $34 \%))$ at the thrombotic event than women who stopped. Out of 332 women using a combined preparation and who received advice from a physician to stop, 39 (12\%) continued to use their current contraceptive.

Conclusions: The finding that women continue their combined oral contraceptive use after receiving advice to stop is a real concern, in particular because this use could increase the risk of a recurrence.

Keywords: Venous thrombosis; Hormonal contraceptive; Guideline; Practice

\section{Introduction}

The WHO guideline "Medical eligibility criteria for contraceptive use" published in 2004 recommends that women with a history of venous thromboembolic disease should refrain from using combined hormonal contraceptives [1]. The same recommendation is stated in national guidelines from the Netherlands $[2,3]$. By law, the manufacturer is required to list contra-indications on package insertions of combined oral contraceptives in the Netherlands. These package insertions advise women to refrain from the use of these contraceptives in case of a (experienced) thromboembolic event. Both national and WHO guidelines state that progestagenonly contraceptives such as progestagen-only pills (POPs) or intra-uterine devices may be used in case of a history of venous thrombosis [1-3].

There is limited knowledge regarding daily medical practice after a hormonal contraceptive-associated venous thrombotic event. To assess the adherence to the recommendations in guidelines, short-term follow-up data on hormonal contraceptive use were analyzed from patients enrolled in the Multiple Environmental and Genetic Assessment of risk factors for venous thrombosis (MEGA) study (a case-control study of venous thrombosis). We focused in particular on what proportion of patients with a hormonal contracep- 
Table 1. General Characteristics

\begin{tabular}{|c|c|c|c|}
\hline & $\begin{array}{l}\text { Women who } \\
\text { stopped }\end{array}$ & $\begin{array}{l}\text { Women who } \\
\text { changed }\end{array}$ & $\begin{array}{l}\text { Women who } \\
\text { continued }\end{array}$ \\
\hline & $\mathrm{N}=\mathbf{5 2 1}$ & $N=63$ & $N=119$ \\
\hline Age, mean (range), years & $36(18-49)$ & $34(20-48)$ & $36(18-49)$ \\
\hline \multicolumn{4}{|l|}{$\mathrm{BMI}^{\mathrm{a}}$} \\
\hline$>30 \%$ & $126(76)$ & $11(7)$ & $29(17)$ \\
\hline $25-30 \%$ & $156(75)$ & $20(10)$ & $33(16)$ \\
\hline$<25 \%$ & $210(73)$ & $29(10)$ & $50(17)$ \\
\hline \multicolumn{4}{|l|}{ Smoking ${ }^{\mathrm{a}}$} \\
\hline Current $(\%)$ & $213(76)$ & $22(8)$ & $45(16)$ \\
\hline Ever $(\%)$ & $89(77)$ & $10(9)$ & $17(15)$ \\
\hline Never $(\%)$ & $203(71)$ & $30(11)$ & $52(18)$ \\
\hline \multicolumn{4}{|l|}{ Positive family history ${ }^{\mathrm{a}}$} \\
\hline Yes $(\%)$ & $115(82)$ & $7(5)$ & $18(13)$ \\
\hline No $(\%)$ & $300(72)$ & $40(10)$ & $75(18)$ \\
\hline \multicolumn{4}{|l|}{ Contraception } \\
\hline Combined oral contraceptives $(\%)$ & $508(75)$ & $60(9)$ & $114(17)$ \\
\hline First generation $(\%)$ & $32(86)$ & $1(3)$ & $4(11)$ \\
\hline Second generation $(\%)$ & $212(76)$ & $13(5)$ & $53(19)$ \\
\hline Third generation (\%) & $213(74)$ & $37(13)$ & $38(13)$ \\
\hline Cyproterone acetate (\%) & $45(64)$ & $8(11)$ & $17(24)$ \\
\hline Drospirenone (\%) & $6(67)$ & $1(11)$ & $2(22)$ \\
\hline Progestagen-only contraceptives (\%) & $12(60)$ & $3(15)$ & $5(25)$ \\
\hline Oral progestagen-only ${ }^{\mathrm{b}}(\%)$ & $0(0)$ & $1(100)$ & $0(0)$ \\
\hline Intra-uterine device $(\%)$ & $0(0)$ & $0(0)$ & $1(100)$ \\
\hline Implanon (\%) & $1(100)$ & $0(0)$ & $0(0)$ \\
\hline Injectables $(\%)$ & $11(65)$ & $2(12)$ & $4(24)$ \\
\hline Unknown (\%) & $1(100)$ & $0(0)$ & $0(0)$ \\
\hline
\end{tabular}

aData on BMI, smoking and family history were available in 665, 682 and 556 women, respectively. ' User of lynestrenol, a first generation progestagen.

tive-associated venous thrombosis stopped, changed, or continued their hormonal contraceptive use and if patients changed, what hormonal contraceptive preparation was used. Secondly, we assessed whether acquired risk factors for venous thrombosis were associated with the decision to stop, change, or continue contraceptive use. In a proportion of these women, long-term follow-up data were available including information on advice from a physician on hormonal contraceptive use after a thrombotic event. In these women, we assessed the proportion of women who were advised to stop their oral contraceptive use and who followed this advice. 


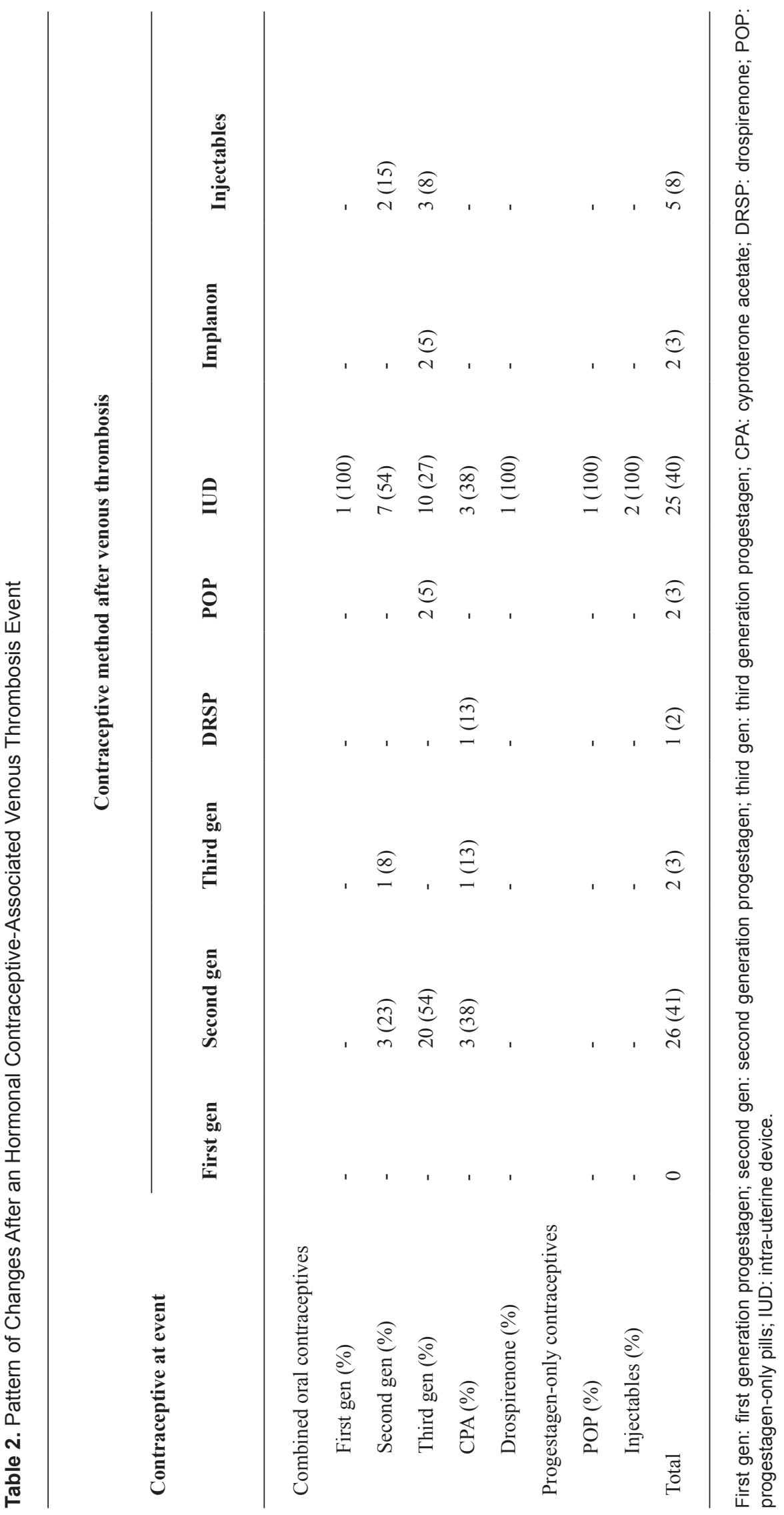




\section{Methods}

\section{Study design}

For this study, we included patients who were enrolled in a large case-control study on risk factors for venous thrombosis, i.e., the MEGA study. Details have been described elsewhere [4]. In short, consecutive patients younger than 70 years with a first symptomatic deep vein thrombosis in the leg or arm or pulmonary embolism were recruited from six anticoagulation clinics in the Netherlands between March 1, 1999 and August 31, $2004(\mathrm{~N}=5,183)$. Control subjects were partners of patients or recruited via random digit dialling.

All patients completed a detailed questionnaire on risk factors for venous thrombosis, including oral contraceptive use. The questions covered a period of 1 year before the thrombotic event. Three months after discontinuation of the anticoagulation therapy, patients were invited to the anticoagulation clinic for a blood sample. During this visit patients were interviewed regarding the period from the venous thrombotic event until the venepuncture. This interview included items on the change of hormonal contraceptive methods since the diagnosis of venous thrombosis. All patients included in the MEGA case-control study subsequently took part in a follow-up study. In the follow-up questionnaire, a question was asked whether or not their physician gave advice on hormonal contraceptive use after the thrombotic event. Because not all patients participated in this follow-up study, data were available in a proportion of included women from the current analysis.

Population of interest were women with a hormonal contraceptive-associated venous thrombosis. Of 5,183 patients included in the MEGA study, 2,799 were women of whom 1,703 were younger than 50 years. Women not taking hormonal contraceptives at the time of a venous thrombosis were excluded $(\mathrm{N}=569)$. Of 431 women no data were available on hormonal contraceptive use after the thrombotic event, i.e., at the time of venepuncture. In total, 703 women were included in the current analysis of which 414 women also filled in the follow-up questionnaire.

\section{Analysis}

We first determined what percentage of women with venous thrombosis during hormonal contraceptive use stopped, continued, or changed their hormonal contraceptive use after the event. Baseline characteristics (i.e., age, body mass index (BMI), current smoking, positive family history and type of contraception) were studied separately for women who stopped, changed, or continued their contraception. BMI was analyzed as a categorical variable with three categories: BMI $<25 \mathrm{~kg} / \mathrm{m}^{2}$, BMI $25-30 \mathrm{~kg} / \mathrm{m}^{2}$ and BMI $>30 \mathrm{~kg} / \mathrm{m}^{2}$. Smoking behavior at the thrombotic event was represented as current, past, or never smokers. A positive family history was defined as having one or more first-degree relatives with a history of venous thrombosis. Contraception was divided into combined hormonal contraceptives (i.e., containing ethinylestradiol and a progestagen) and progestagen-only contraceptives. The most commonly used administration route for combined formulations is orally but occasionally it is administered transdermally or transvaginally. Progestagenonly formulations are administered orally (mini pill) as well as subcutaneously (via implant or injection) or intrauterinely (intrauterine device). In our study, none of the women used a combined transdermal patch or combined vaginal ring. All other applications of hormones were used. Combined oral contraceptives were further subdivided according to the type of progestagen used: first generation (i.e., lynestrenol and norethisteron), second generation (i.e., levonorgestrel) and third generation combined oral contraceptives (i.e., gestodene, desogestrel and norgestimate). The progestagens introduced onto the market after the third generation progestagens, i.e., cyproterone acetate and drospirenone, were analyzed separately. Progestagen-only contraceptives were subdivided into oral progestagen-only contraceptives (the so-called POPs), hormonal intra-uterine device, implants and injectables.

Secondly, we assessed which type of hormonal contraceptive women used when they changed their hormonal contraceptive use after the thrombotic event.

Thirdly, we determined whether exposure to an acquired risk factor for venous thrombosis was associated with stopping, changing, or continuing to use hormonal contraceptives. The following acquired risk factors were taken into account: surgery, plaster cast, immobilization, injury and travel. A thrombotic event was classified as secondary to surgery, plaster cast, immobilization, or injury when one or more of these risk situations had occurred within 3 months prior to the thrombotic event. A thrombotic event was classified as secondary to travel when a patient had travelled for more than $4 \mathrm{~h}$ in the period of 8 weeks prior to the thrombotic event.

Finally, in women with data on advice received from a physician, we determined what percentage of women stopped, changed, or continued their contraceptive use when they were advised to stop.

Risk differences (RDs) with 95\% confidence intervals (95\% CI) were calculated between different proportions. The Newcombe method 10 was used to calculate these RDs as this method performed better with low sample sizes [5]. All statistical analyses were performed with STATA, version 12.0 (Statacorp LP, College Station, TX, USA).

\section{Results}

A total of 703 women with a hormonal contraceptive-as- 


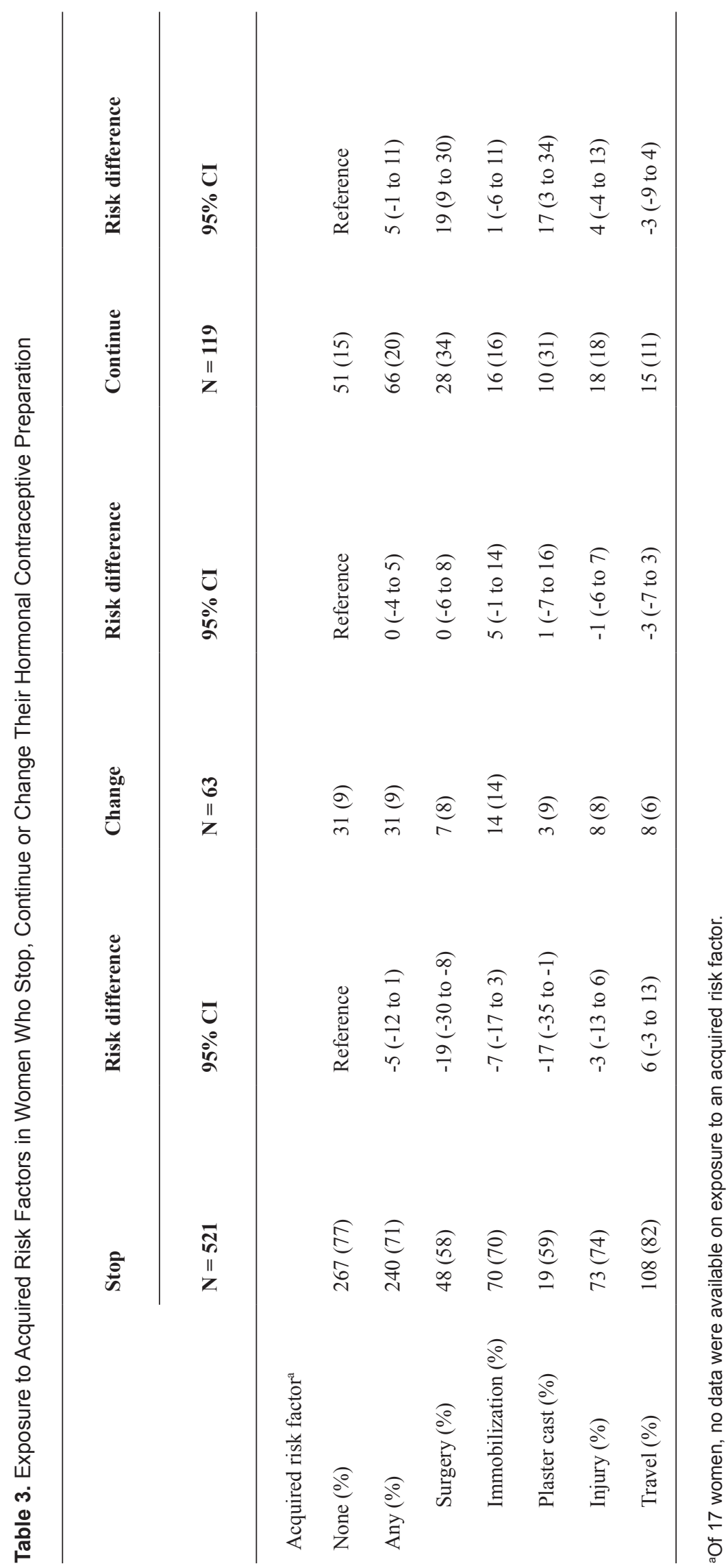


sociated venous thrombosis provided information on contraceptive use after the thrombotic event. At an average of 10.8 months (range: 2.1 - 35.4 months) after the thrombotic event, 521 (74\%) women had stopped using hormonal contraceptives, $63(9 \%)$ changed to another hormonal contraceptive and $119(17 \%)$ had continued using the same contraceptive.

General characteristics of the study population are presented in Table 1 for women who stopped, changed, or continued hormonal contraceptives. On average, women were about the same age (stop: 36 years (range 18 - 49), change: 34 years (range $20-48$ ) and continue: 36 years (range 18 - 49)). The proportion of women stopping, changing, or continuing their hormonal contraceptive did not markedly differ between BMI categories or smoking behavior. Women with a positive family history of venous thrombosis were more likely to stop and less likely to change or continue their hormonal contraceptive than women without a positive family history. The vast majority was using a combined preparation at the time of venous thrombosis and the most commonly used progestagen was a second or third generation progestagen. Women using a combined oral contraceptive were more likely to stop and less likely to change or continue their contraceptive than women using a progestagen-only contraceptive. While no difference in age was observed, users of a first generation progestagen in their combined oral contraceptive were more likely to stop their contraceptive, and users of cyproterone acetate and drospirenone were more likely to continue their contraceptive than users of other progestagens.

An overview of the contraceptive used at the event and after event among women who changed their contraceptive is given in Table 2 . The majority of these women changed to either a second generation combined oral contraceptive $(41 \%)$ or to an intra-uterine device $(40 \%)$. Fifty-four percent of third generation combined oral contraceptive users changed to a second generation contraceptives, while 54\% of second generation combined oral contraceptive users changed to an intra-uterine device (Table 2).

Regarding adherence to the guidelines, of 682 women who were using a combined oral contraceptive at the venous thrombosis event, $508(74 \%)$ women discontinued use of combined oral contraceptives. However, 143 (21\%) either changed to another combined oral contraceptive or continued to use their combined preparation. Thirty-one (5\%) women changed to progestagen-only preparations.

At the time of interview not all women had stopped anticoagulant therapy. Hormonal contraceptive use might be continued to prevent pregnancy during anticoagulant therapy. Sixty-four $(10 \%)$ women were using anticoagulant therapy at time of the interview. After excluding these women, the proportion of women who stopped, changed or continued their contraceptive did not change; 421 (76\%) women stopped, 46 (8\%) changed and 85 (15\%) continued their con-

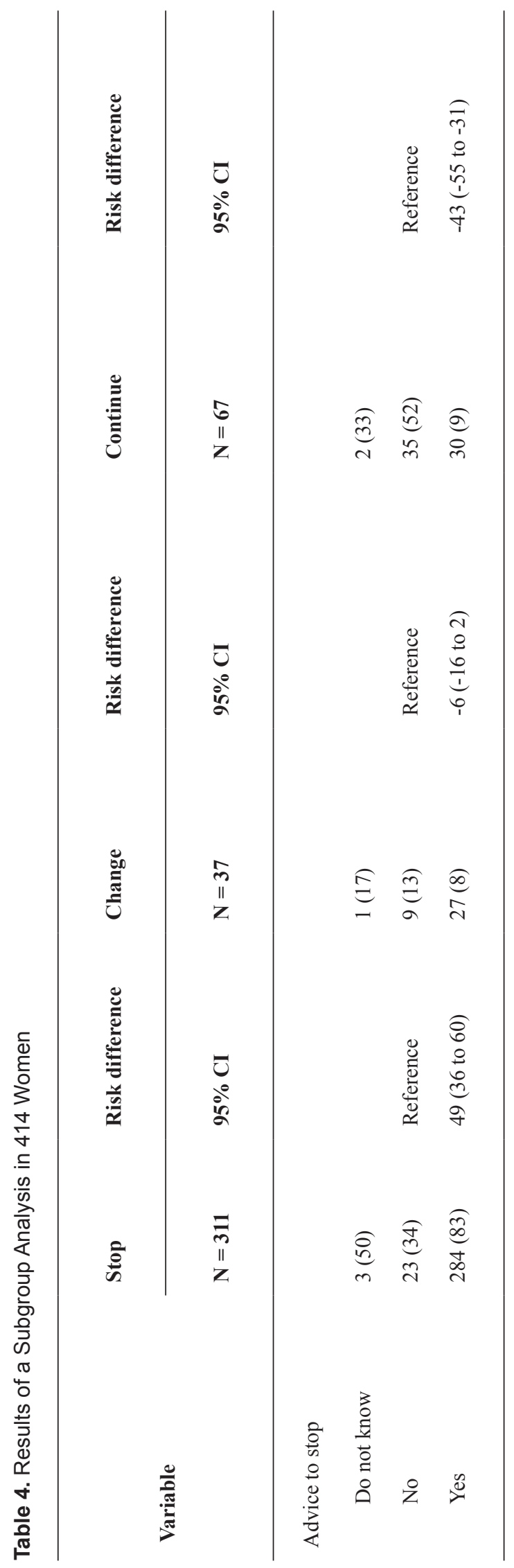


traceptive use.

RDs in acquired risk factors - surgery, plaster cast, immobilization, injury and travel - for the women who stopped, continued, or changed their contraceptive method are presented in Table 3 . Women who had undergone surgery within 3 months prior to the diagnosis of thrombosis were less likely to stop their contraceptive use than unexposed women ( $58 \%$ versus $77 \%$, RD $-19 \%$ (95\% CI: -30 to -8$)$ ) and more likely to continue their contraceptive use (34\% versus $15 \%$, RD 19\% (95\% CI: 9 to 30)). Women who had a plaster cast within 3 months prior to the diagnosis of thrombosis were less likely to stop their contraceptive use than unexposed women (59\% versus $77 \%$, RD $-17 \%$ (95\% CI: -35 to -1$)$ ) and more likely to continue their contraceptive use (31\% versus $15 \%$, RD $17 \%$ (95\% CI: 3 to 34$)$ ). Regarding women exposed to immobilization, injury or travel, no differences were observed between exposed and unexposed women.

Out of 414 women, $341(82 \%)$ were advised to stop using hormonal contraceptives, while 67 (16\%) women did not receive this advice. Women who received advice regarding hormonal contraceptive use were more likely to stop their contraceptive use than women who did not receive any advice ( $83 \%$ versus $34 \%$, RD $49 \%$ (95\% CI: 36 to 60 )) (Table 4). Of 332 women using a combined oral contraceptive who were advised to stop, 277 (83\%) did stop their preparation, $16(5 \%)$ changed to progestagen-only contraceptives and $39(12 \%)$ either continued or changed to another combined preparation.

\section{Interpretation}

In this study we found that the majority of women with a first episode of venous thrombosis while using a hormonal contraceptive method had discontinued the use of hormonal contraceptives after the thrombotic event. However, about $25 \%$ of these women either changed or continued their contraceptive. Anticoagulant therapy at the time of interview did not explain why women continued their contraceptive use. Women who had had a thrombosis following surgery or plaster cast continued their hormonal contraceptive method more often than unexposed women. The majority of the women who received advice to stop using their hormonal contraceptive, did follow this advice.

The majority of women changing oral contraceptives, change to a combined preparation with a second generation progestagen or an intra-uterine device. The reason behind changing to a second generation combined oral contraceptive may be the lower risk for venous thrombosis in these users compared with either third generation or cyproterone acetate users [6-9]. However, these risk estimates are for a first event and whether these estimates can also be applied to a second event is unclear.

The association between the presence of certain acquired risk factors (surgery or a plaster cast) and the continuation of oral contraceptive use suggests that physicians think it is safe to continue oral contraceptives when a strong acquired risk factor for thrombosis has been established as an (additional) cause of the thrombotic event. Venous thrombosis is a multicausal disease, i.e., for the occurrence of deep vein thrombosis a combination of risk factors needs to be present [10]. The recurrence rate in surgically provoked events is low in patients without other clinical risk factors [11, 12], whether this is also the case in women with a surgically provoked thrombotic event who use and continue to use oral contraceptives is unknown. It is therefore unclear whether the continuation of combined oral contraceptives is justified in this subgroup of patients.

Little is known about hormonal contraceptive use after venous thrombosis in clinical practice and about the risk of a recurrence in hormonal contraceptive users. The recommendations in the WHO guideline are based on studies which only included first events. No data on second events were available before publication of the WHO guideline in 2004 . Only one study, which was published in 2010, analyzed the recurrence rate of thromboembolic disease in women who had actually continued or stopped oral contraceptive use after their first episode of oral contraceptive-associated venous thrombosis. They found an increased rate for recurrent venous thrombosis in hormonal contraceptive users compared to non-users [13]. However, only 11 recurrences were found among hormonal contraceptive users. The number became too low per type of contraceptive to infer any other conclusions.

We had detailed information on contraceptive use before and after venous thrombosis, as well as on acquired risk factors. Therefore we were able to examine whether the presence of these risk factors was associated with the decision to stop or continue oral contraceptives, although we do not know whether this was actually taken into account in the decision making. Although we know whether these women were advised to stop their contraceptive use, we do not know why women stopped, changed or continued their contraceptive use. In particular, in women who received advice to stop using their contraceptive, it would be beneficial to know their reason for continuing their contraceptive. In the Netherlands, the WHO guideline is implemented in national guidelines and we observed that about $20 \%$ do not follow the advice from the physician to stop their contraceptive use. The percentage of women receiving no advice may be different per country depending on implementation of guidelines. However, the issue that women continue their combined oral contraceptive use after receiving advice to stop is a real concern.

In conclusion, the fact that women seemed to disregard the advice from a physician is a real concern, emphasized by the potential increased risk of a recurrence when continuing hormonal contraceptives. 


\section{Author Contributions}

All authors contributed to the conception and design of the study, analysis and interpretation of the data, and drafting of the manuscript. All authors approved the final version of the manuscript. Bernardine H. Stegeman, Frits R. Rosendaal and Astrid van Hylckama Vlieg had full access to all of the data in the study and take responsibility for the integrity of the data and the accuracy of the data analysis.

\section{Grant Support}

The MEGA study was supported by grant NHS 98.113 from the Netherlands Heart Foundation, grant RUL 99/1992 from the Dutch Cancer Foundation and grant 912-03-033|2003 from the Netherlands Organization for Scientific Research. The follow-up of this study was supported by grant 2008B086 from the Netherlands Heart Foundation. BHS was supported by grant 40-00812-98-07-045 from the Netherlands Organization for Scientific Research.

\section{Competing Interests}

None declared.

\section{References}

1. WHO. Medical eligibility criteria for contraceptive use. World Health Organization [serial online] 2010. Available: http://whqlibdoc.who.int/publications/2004/9241562668.pdf (accessed March 7, 2012).

2. CBO. Diagnostiek, preventie en behandeling van veneuze trombo-embolie en secundaire preventie van arteriele trombose. Centraal BegeleidingsOrgaan [serial online] 2009. Available: http://www.cbo.nl/thema/Richtlijnen/Overzicht-richtlijnen/Cardiovasculaire-aandoening/ (accessed March 7, 2012).

3. NHG. Samenvattingskaart anticonceptie. Nederlands Huisartsen Genootschap [serial online] 2011. Available: http://nhg.artsennet.nl/kenniscentrum/k_richtlijnen $/ \mathrm{k}_{-}$
nhgstandaarden/Samenvattingskaartje-NHGStandaard/ M02_svk.htm (accessed March 7, 2012).

4. Blom JW, Doggen CJ, Osanto S, Rosendaal FR. Malignancies, prothrombotic mutations, and the risk of venous thrombosis. JAMA. 2005;293(6):715-722.

5. Newcombe RG. Interval estimation for the difference between independent proportions: comparison of eleven methods. Stat Med. 1998;17(8):873-890.

6. Bloemenkamp KW, Rosendaal FR, Helmerhorst FM, Buller HR, Vandenbroucke JP. Enhancement by factor V Leiden mutation of risk of deep-vein thrombosis associated with oral contraceptives containing a third-generation progestagen. Lancet. 1995;346(8990):1593-1596.

7. Jick H, Jick SS, Gurewich V, Myers MW, Vasilakis C. Risk of idiopathic cardiovascular death and nonfatal venous thromboembolism in women using oral contraceptives with differing progestagen components. Lancet. 1995;346(8990):1589-1593.

8. Jick H, Kaye JA, Vasilakis-Scaramozza C, Jick SS. Risk of venous thromboembolism among users of third generation oral contraceptives compared with users of oral contraceptives with levonorgestrel before and after 1995: cohort and case-control analysis. BMJ. 2000;321(7270):1190-1195.

9. Effect of different progestagens in low oestrogen oral contraceptives on venous thromboembolic disease. World Health Organization Collaborative Study of Cardiovascular Disease and Steroid Hormone Contraception. Lancet. 1995;346(8990):1582-1588.

10. Rosendaal FR. Venous thrombosis: a multicausal disease. Lancet. 1999;353(9159):1167-1173.

11. Baglin T, Luddington R, Brown K, Baglin C. Incidence of recurrent venous thromboembolism in relation to clinical and thrombophilic risk factors: prospective cohort study. Lancet. 2003;362(9383):523-526.

12. Hansson PO, Sorbo J, Eriksson H. Recurrent venous thromboembolism after deep vein thrombosis: incidence and risk factors. Arch Intern Med. 2000;160(6):769-774.

13. Christiansen SC, Lijfering WM, Helmerhorst FM, Rosendaal FR, Cannegieter SC. Sex difference in risk of recurrent venous thrombosis and the risk profile for a second event. J Thromb Haemost. 2010;8(10):21592168. 